\title{
There is Time to Adjust. Aging as a Protective Factor for Autism
}

\author{
Diego Iacono ${ }^{1,2,3 *}$ \\ ${ }^{1}$ Biomedical Sciences, Biomedical Research Institute of New Jersey (BRInj), USA \\ ${ }^{2}$ Neuropahology Research, BRInj and Mid-Atlantic Neonatology Associate (MANA), USA \\ ${ }^{3}$ Atlantic Neuroscience Institute, Atlantic Health System (AHS), USA
}

*Corresponding author : Diego Iacono, Neuropathology research, Biomedical Research Institute of NJ, BRInj, 140 E. Hanover Avenue, Cedar Knolls, NJ 07927, USA

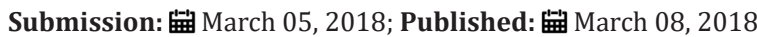

\section{Opinion}

Autism spectrum disorder (ASD) is formally diagnosed before the age of 3 that is, when the central nervous system (CNS) is not yet completely formed, but it is mature enough to generate behavioural abnormalities in some individuals when compared to an agematched group of typically developed children [1,2]. However, ASD is not a life-threating disease and children diagnosed with ASD age at the same rate as their peers. The possible detrimental or beneficial factors associated with aging in children affected by ASD are not fully known. Surprisingly, the amount of peer-reviewed medical and scientific international literature published on the topic of aging with autism is quite modest and sporadic [3]. The scarcity of aging-ASD investigations derives from the lower level of attention, and related funding opportunities, from the major public and private funding agencies for research across the globe. This scientific and funding gap is particularly surprising when considering two aspects: on one side, the marked increasing of elder populations across the globe, and on the other side, the improvement of the criteria and diagnostic tools to diagnose ASD, which has determined indeed a real increase of the rate of children diagnosed with ASD (https://www.cdc.gov/ncbddd/autism/data. html).

ASD is clinically characterized by a series of highly pervasive social, cognitive and sensory-motor abnormalities that belong in part, to the same behavioural aspects and cognitive domains involved in either successful (e.g. absence of behavioural-cognitive deficits in a nonagenarian or centenarian person until death) and pathologic aging (e.g. dementia). However, by definition, ASD is not dementia (which presupposes a previous status of healthy cognition and consequent decay) and actually, it is not rare the case that some ASD children can have an enhancement of specific cognitive skills (e.g. memory) that can be scored at a higher levels than their children-mates [4-7]. Frequently, ASD-related behavioral and cognitive aspects become corrected or adjusted in a consistent number of subjects during the pediatric and young adult ages, allowing most of these people to perform different and numerous types of skills like every other person of the same age, or in some cases, even at a higher level of efficiency [8-10]. So, is the aging per se a protective factor for a more successful life in ASD children [11-14]. If so, are the same protective factors for dementia such as higher education, a specific genotype (e.g. APOE), physical activities, care of blood-pressure and cholesterol levels, socializing and amusing activities, etc. protective or beneficial factors for ASD children as well? These general considerations should prompt both neurodevelopment and gerontology investigators to collaborate focusing on this area of research.

In particular, longitudinal studies of ASD-children ranging till their older age should be proposed and implemented by both public-based and private funding organizations to encourage interested investigators and research institutions to follow up a consistent number of ASD subjects and use all possible imaging, neuropsychological, neurophysiological and genetic armamentarium currently available. Moreover, specific brain donation programs as the final phase of an ASD-aging longitudinal study should be proposed in order to decipher and identify the peculiar neuro-architectonic features or lesion characteristics of both ASD-brains and aging-ASD related changes. We are strongly convinced that both fields of research, neuro-developmental and gerontology science, could find mutual advantages from these types of studies with the ultimate benefit of the ASD patients and their families.

\section{References}

1. Kanner L (1943) Autistic disturbances of affective contact. Nervous Child 2: 217-249.

2. American Psychiatric Association (2013) Diagnostic and statistical manual of mental disorder ( $5^{\text {th }}$ edn), American Psychiatric Publishing, Arlington, USA.

3. Wise EA, Smith MD, Rabins PV (2017) Aging and Autism Spectrum Disorder: A Naturalistic, Longitudinal Study of the Comorbidities and Behavioral and Neuropsychiatric Symptoms in Adults with ASD. J Autism Dev Disord 47(6): 1708-1715.

4. Seltzer MM, Shattuck P, Abbeduto L, Greenberg JS (2004) Trajectory of development in adolescents and adults with autism. Mental Ment Retard Dev Disabil Res Rev 10(4): 234-247. 
5. Magiati I, Tay XW, Howlin P (2014) Cognitive, language, social and behavioural outcomes in adults with autism spectrum disorder: A systematic review of longitudinal follow-up studies in adulthood. Clin Psycho Rev 34(1): 73-86

6. Lever AG, Geurts HM (2018) Is Older Age Associated with Higher Self- and Other-Rated ASD Characteristics? J Autism Dev Disord. doi: 10.1007/s10803-017-3444-2.

7. Howlin P, Magiati I (2017) Autism spectrum disorder: outcomes in adulthood. Curr Opin Psychiatry 30(2): 69-76.

8. Koffer Miller KH, Mathew M, Nonnemacher SL, Shea LL (2017) Program experiences of adults with autism, their families, and providers: Findings from a focus group study.

9. Braden BB, Smith CJ, Thompson A, Glaspy TK, Wood E, et al. (2017) Executive function and functional and structural brain differences in middle-age adults with autism spectrum disorder. Autism Res 10(12): 1945-1959.
10. Barron Linnankoski S, Reinvall O, Lahervuori A, Voutilainen A, Lahti Nuuttila P, et al. (2015) Neurocognitive performance of children with higher functioning autism spectrum disorders on the NEPSY-II. Child Neuropsychol 21(1): 55-77.

11. Cheng CH, Chan PS, Hsu SC, Liu CY (2017) Meta-analysis of sensorimotor gating in patients with autism spectrum disorder. Psychiatry Res. pii: S0165-1781(17)30450-X

12. Hwang YIJ, Foley KR, Trollor JN (2017) Aging well on the autism spectrum: the perspectives of autistic adults and carers. Int Psychogeriatr 29(12): 2033-2046.

13. Powell PS, Klinger LG, Klinger MR (2017) Patterns of Age-Related Cognitive Differences in Adults with Autism Spectrum Disorder. J Autism Dev Disord 47(10): 3204-3219.

14. Oberman LM, Pascual Leone A (2014) Hyperplasticity in Autism Spectrum Disorder confers protection from Alzheimer's disease. Med Hypotheses 83(3): 337-342.

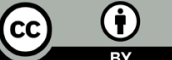

Creative Commons Attribution 4.0 International License

For possible submissions Click Here
Submit Article

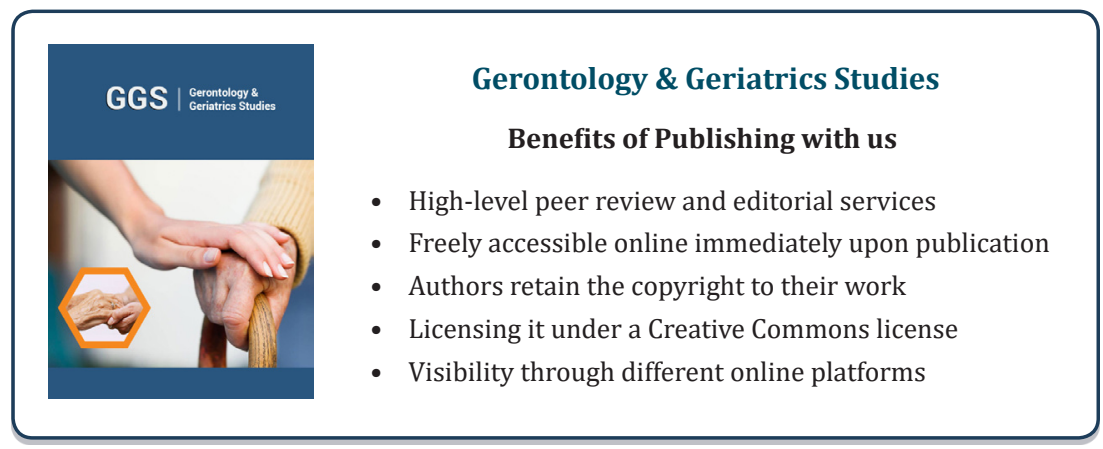

